\title{
Imaging of the Optic Nerve with Standardised Echography
}

\author{
H. R. ATTA \\ Wolverhampton
}

\begin{abstract}
Summary
Standardised echography is a unique method of ophthalmic ultrasound that requires special instrumentation, well prescribed methods of examination and a high level of operator skill. Because of its anatomical features and position in the orbit, the optic nerve is well suited for imaging by this technique, particularly for the detection of subtle lesions in its anterior portion and nerve head. Standardised A-scan can measure precisely the width of the nerve, differentiate between fluid and solid lesions as a cause of nerve swelling (the $30^{\circ}$ test) and, by examining reflectively and internal structure, provide "ecographic tissue diagnosis" in a high proportion of cases. Contact B-scan is suitable for detecting lesions of the optic disc (drüsen, swelling and large cupping), calcification in the nerve (meningioma, deep drüsen), and for the topographic display of lesions. CT-scan is superior in displaying the apical and intra-cranial portion of the nerve, and the simultaneous presentation of both orbits, peri-orbital structures and bony walls.
\end{abstract}

Standardised echography is a system-of ophthalmic ultrasound that was developed in the early 1970 s by Karl Ossoinig. ${ }^{1,2}$ A unique feature of this method is the specifically designed "standardised" A-scan which incorporates a special S-shaped amplifier and a pre-determined "tissue sensitivity" described level. The completed kit for standardised echography includes contact real-time B-scan and Doppler unit. A methodical system of examination has been developed to ensure standardisation of techniques and collection of all the acoustic criteria needed to reach "echographic tissue diagnosis" $3,4,5$ (Table I).

The optic nerve is well suited to echographic imaging because of its regular tubular structure consisting of "low reflective" nerve proper and "highly reflective" peri-neural sheaths, surrounded by the heterogeneous orbital fat. Standardised echography may therefore be a method of choice in detecting subtle changes in the nerve and in providing tissue differentiation of its lesions.

In this study the various methods of displaying the optic nerve with A and B-scans are described and the merits of each technique, particularly in relation to CTscan, are discussed. Two examples of nerve lesions demonstrating the value of standardised echography are also presented.

\section{Methods of Examination}

\section{Instruments:}

Two standardised A-scan instruments are available currently ie Kretztechnik 7200MA and Ophthascan S. Ophthascan S is also equipped with high resolution contact $\mathrm{B}$ -

From: Wolverhampton and Midland Counties Eye Infirmary.

Correspondence to: Mr. H. R. Atta, FRCS, Department of Ophthalmology, Aberdeen Royal Infirmary, Aberdeen. 
scan. Both instruments were used in this study. Doppler unit is not required for optic nerve evaluation. The "tissue sensitivity" decibel level of the A-scan was determined before examinations using a "tissue model" as described by Till and Ossoinig. ${ }^{6,7}$

\section{Patient Preparation:}

After explaining the procedure, the patient is seated in a reclining position with the

Table I Standardised Echography. System of Examination

\begin{tabular}{ll}
\hline \multicolumn{1}{c}{ Examination } & $\begin{array}{l}\text { Acoustic Information } \\
\text { 1. Basic Screening }\end{array}$ \\
20 detect the presence of \\
lesions \\
3. Topographic & $\begin{array}{l}\text { Location } \\
\text { Shape } \\
\text { Borders }\end{array}$ \\
4. Kinetic & $\begin{array}{l}\text { Structure } \\
\text { Reflectivity } \\
\text { Sound Attenuation } \\
\text { Consistency } \\
\text { Vascularity } \\
\text { Mobility }\end{array}$ \\
\hline
\end{tabular}

Basic screening of the orbit is carried out with standardised A-scan, supplemented with contact B-scan. If lesion is detected, special examinations are carried out ie Topographic (B and A scan), Quantitative (A-scan) and Kinetic (A-scan and Doppler). Nine acoustic informations can be obtained to formulate "echographic tissue diagnosis". $3,4,5$

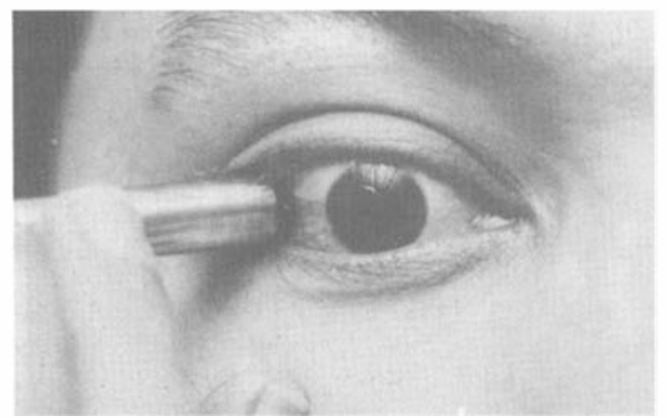

examiner sitting to the right, facing the instrument, with its oscilloscope as near to the patient's head as possible. A fixation light is required to maintain patient's gaze at the desired position during examination. Topical anaesthetic is instilled into both eyes. The probe is placed directly on the globe. This has the advantage of ensuring that the patient's gaze is in the correct position and for obtaining maximum resolution of image. For the B-scan a coupling medium (methylcellulose) is required to maintain adequate sound transmission.

\section{Standardised A-scan examination: (Fig 1 )}

The instrument is set at tissue sensitivity and the patient fixates at the primary gaze. The probe is placed at the temporal equator, resting on the orbital bony rim and directed posteriorly, nasally and slightly superiorly (Fig 1a). When centred in the beam, the nerve appears as a distinct defect in the orbital fat pattern (Fig 1b). This defect consists of two smooth, steeply rising spikes originating from the nerve sheaths separated by a short chain of very low amplitude spikes representing the nerve proper. The nerve is scanned anterio-posteriorly while the examiner maintains the amplitude of the sheaths spikes as high as possible. This becomes more difficult, however, towards the posterior third of the nerve due to the, increasingly oblique, sound beam incidence. The width of the nerve can be measured

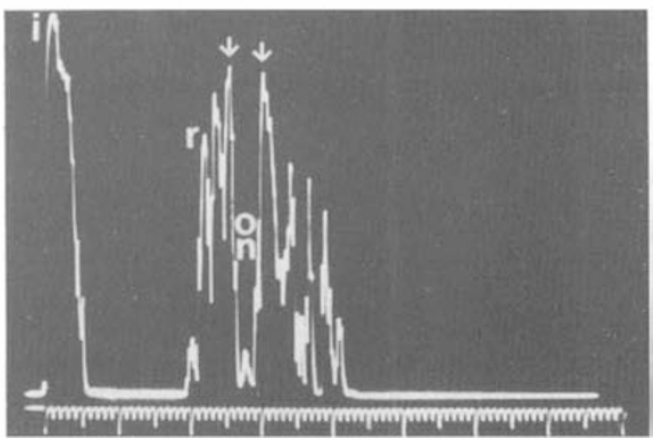

Fig. 1. Standardised A-scan examination of the optic nerve. The patient fixates at the primary position and the probe is placed on the temporal equator and directed posteriorly, nasally and slightly superiorly (a). When perpendicular to the beam, the nerve appears as a distinct defect in the orbital pattern $(b)$ and consists of two steeply rising, tall, sheaths spikes (arrows) separated by the low reflective nerve proper (on). I=initial spike $R=$ retinal spike 
precisely between the two sheaths spikes along its anterior two thirds. When thickened it may also be measured more posteriorly.

\section{Contact B-scan examination:}

A marker is normally located near the tip of the B-probe which indicates the direction of the sound beam and the orientation of the echograph on the display screen. Images of the nerve are best obtained using mediumlow decibel levels of system sensitivity. It is also essential to use the same decibel level if the size of the two fellow nerves is to be compared. Depending on the position of the probe and direction of sound beam; the nerve can be displayed by three different sections:

\section{Axial Section (Fig 2)}

The patient fixates at the primary position, and the probe is placed on the cornea with its marker at the nasal horizontal meridian for horizontal axial and 12 o'clock meridian for vertical axial display. In all axial sections, the lens (L) and optic nerve void (ON), are centred in the echogram. This section is used to demonstrate abnormalities of the nerve head, but because of sound attenuation by the lens, it is of limited use in evaluating the deeper portion of the nerve.

\section{Longitudinal Section (Fig 3)}

The eye is adducted and the probe is placed temporally with its marker on the limbus at the temporal horizontal meridian. By avoiding the cornea and lens, a better resolution of the optic disc and anterior portion of the nerve is obtained. "Optic nerve doubling" described by Coleman et $\mathrm{al}^{8}$ and calcification in the nerve are best seen on this section.
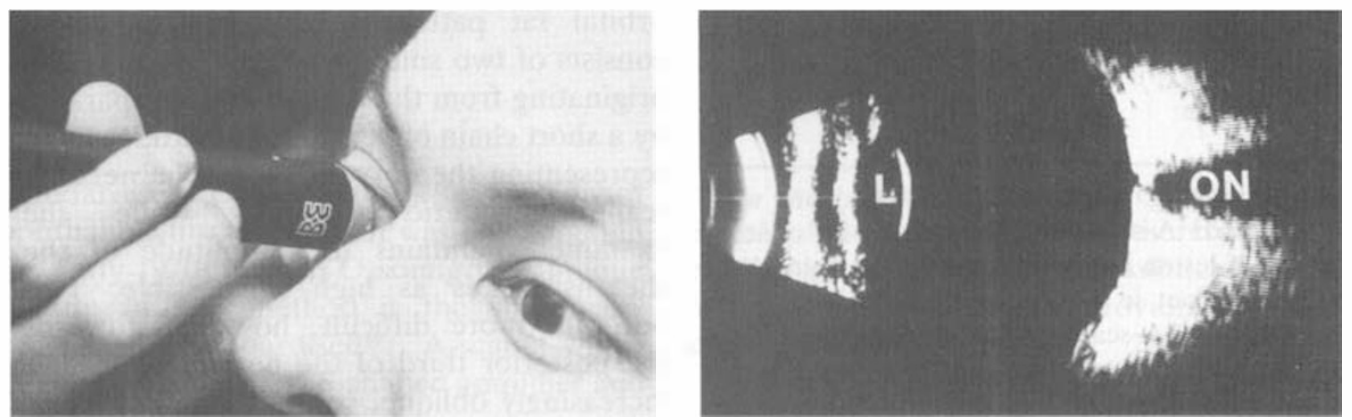

Fig. 2. Axial B-scan display. The probe is centred on the cornea as the patient fixates at the primary position (a). In this illustration the marker on the probe is located nasally, producing a horizontal axial view. $O n$ an axial echogram $(b)$ the lens $(L)$ and optic nerve $(O N)$ are centred in the picture
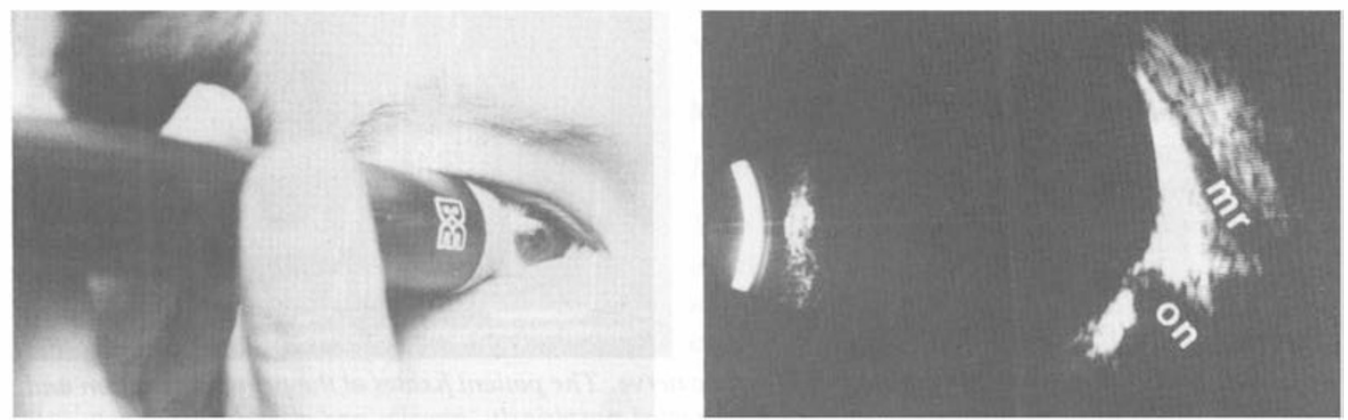

Fig. 3. Longitudinal B-scan display. The patient adducts the eye. The probe is placed temporally with its marker on the limbus at the temporal horizontal meridian, avoiding the cornea $(a)$. In the echogram (b) structures along the nasal horizontal meridian are displayed. $O N=$ optic nerve $M R=$ medial rectus muscle. 


\section{Transverse Section: (Fig 4)}

The patient fixates at the primary position and the probe is placed at the temporal equator with its marker up. The sound beam is directed posteriorly and nasally. An oblique cross section of the nerve is displayed (salami cut). This appears as a round or oval void behind the posterior ocular wall with increasing distances as the nerve is traced more posteriorly. Due to attenuation and oblique sound beam incidence, the posterior third of the normal nerve is not adequately visualised. A cross section view of "the nerve doubling" can occasionally be seen and, by using the same system sensitivity, this display can be used to compare width of the two fellow nerves.

\section{The $30^{\circ}$ Test (Figs 5 and 6)}

This test, well described by Ossoinig, Cennamo and Byrne, ${ }^{9,10}$ utilises kinetic echography to differentiate increased subarachnoid fluid from solid thickening of the peri-neural sheaths or nerve proper. It is performed with standardised A-scan, at tissue sensitivity, when there is evidence of increased optic nerve diameter. Maximum width of the nerve is measured at the primary position and again with the patient refixating $30^{\circ}$ towards the probe. If increased subarachnoid fluid is present, stretching of the nerve sheaths on abduction causes redistribution of fluid and net reduction of nerve diameter. A reduction of more than $10 \%$ is considered positive. ${ }^{9,10}$ An insignificant reduction, or no reduction in width, however, indicates solid nerve or sheath thickening. (Table II).

\section{Case 1, Optic Disc Drusen (Fig 7)}

A 27-year-old female patient was referred by her optometrist with suspected papilloedema. Disc drüsen were readily recognised in one eye but not in the other due to their deep-seated position (Fig 7a). Contact B-scan demonstrated brightly lit lesions on both nerve heads due to the high calcium content of nerve drüsen (Figs $7 b, c, d$ ). Quantitative echography with standardised A-scan confirmed the high reflective nature of these lesions (Figs 7e, f).

\section{Case 2, Increased Subarachnoid Fluid (Fig 8)}

A 40-year-old female patient presented with a history of headache. She was obese and hypertensive. Fundoscopy showed disc swelling

Table II Conditions where positive and negative $30^{\circ}$ tests are found

\begin{tabular}{|c|c|}
\hline Positive $30^{\circ}$ test & Negative $30^{\circ}$ test \\
\hline $\begin{array}{l}\text { Increased intracranial } \\
\text { pressure }\end{array}$ & $\begin{array}{l}\text { Grave's optic } \\
\text { neuropathy }\end{array}$ \\
\hline Optic neuritis & Optic neuritis \\
\hline Apical mass lesion & $\begin{array}{l}\text { Nerve sheath } \\
\text { meningioma }\end{array}$ \\
\hline Trauma & Optic nerve glioma \\
\hline
\end{tabular}

Uveal effusion syndrome

Arachnoid cyst

The $30^{\circ}$ test $^{9,10}$ is performed with standardised A-scan at "tissue sensitivity". The test is positive when a reduction of optic nerve width of more than $10 \%$ is recorded on $30^{\circ}$ lateral gaze, indicating increased subarachnoid fluid.

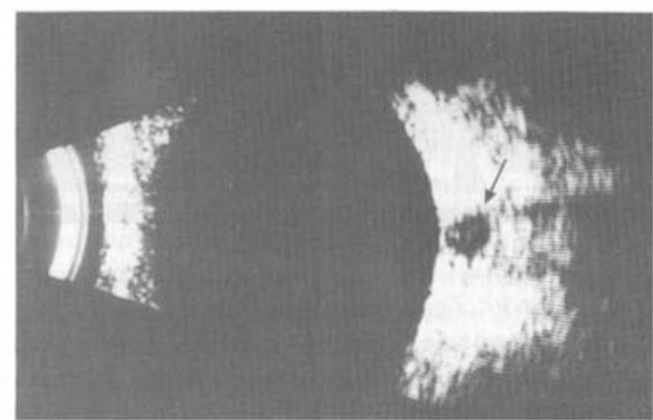

Fig. 4. Transverse B-scan display. With the eye at the primary position, the probe is placed, marker up and directed similar to the A-scan on Figure 1. (a). A cross section of the nerve is displayed (arrow) $(b)$. The distance between the nerve and ocular wall increases as the nerve is scanned more posteriorly. 


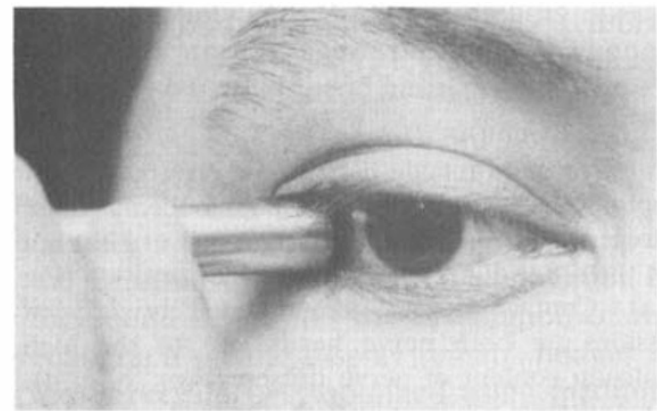

a

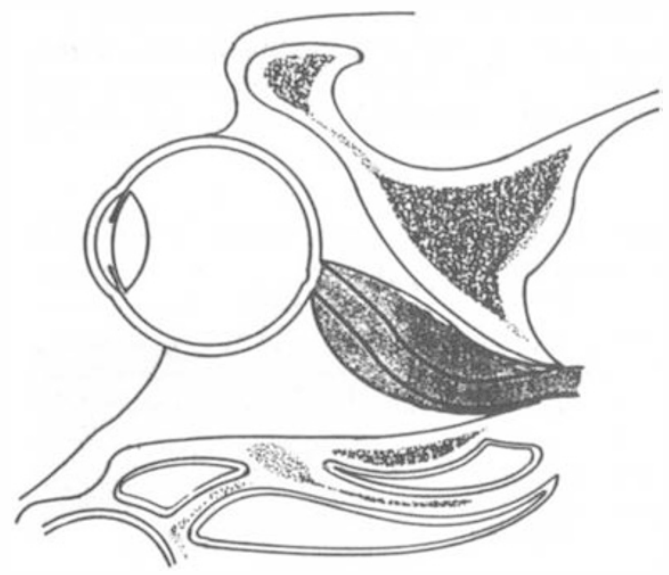

b

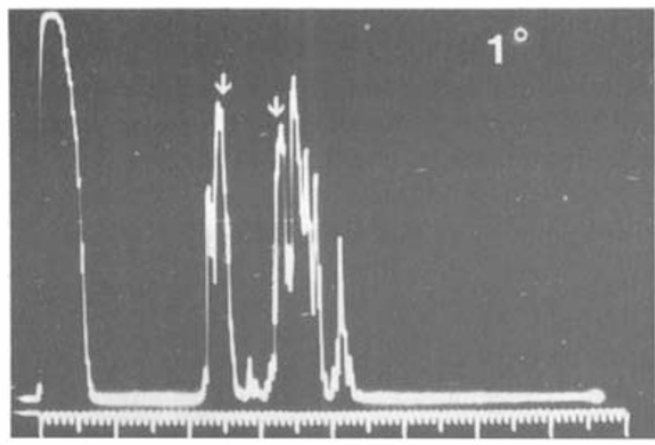

c

Fig. 5. The $30^{\circ}$ Test. Scanning at the primary gaze. Maximum diameter of the nerve is measured at the primary gaze with $A$-scan (a). If the nerve sheaths are distended from increased subarachnoid fluid (b) the width of the nerve defect on the echogram is increased (Fig. 5c). In this case it measures $4.4 \mathrm{~mm}$. Arrows $=$ sheaths spikes.

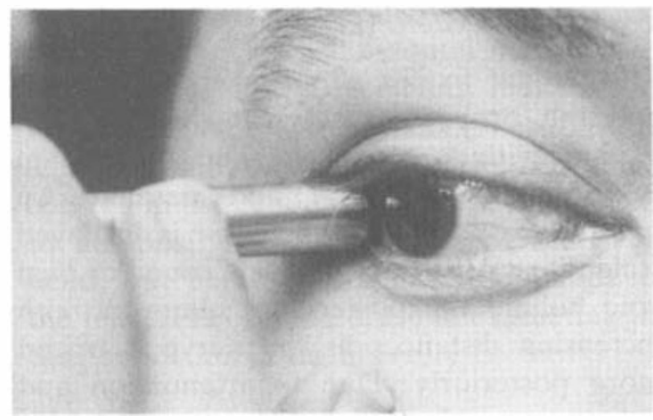

a

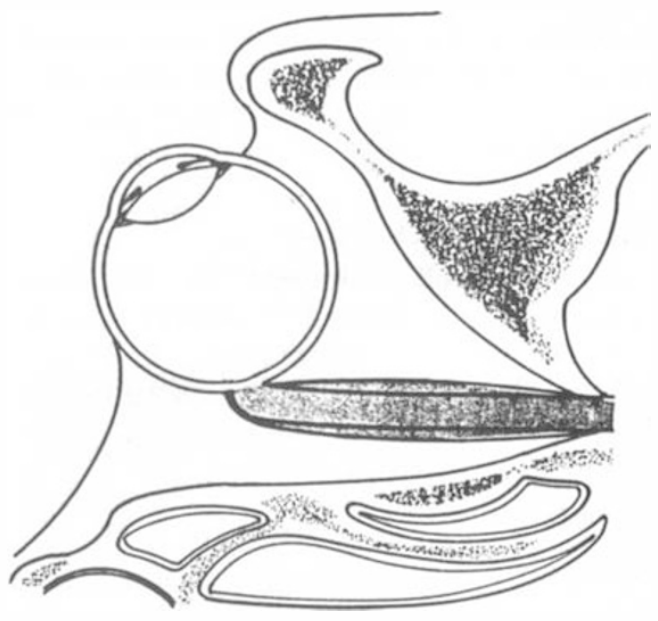

b

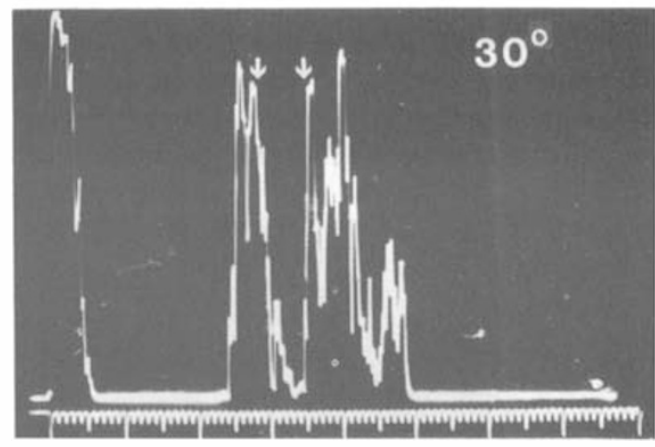

c

Fig. 6. The $30^{\circ}$ Test. Scanning at $30^{\circ}$ lateral gaze. The patient fixates $30^{\circ}$ temporally (a). Traction on the nerve produces redistribution of fluid and reduction of nerve width (b). On the echogram (c) the measurement has been reduced to $3.1 \mathrm{~mm}$ indicating positive $30^{\circ}$ test and increased subarachnoid fluid. 

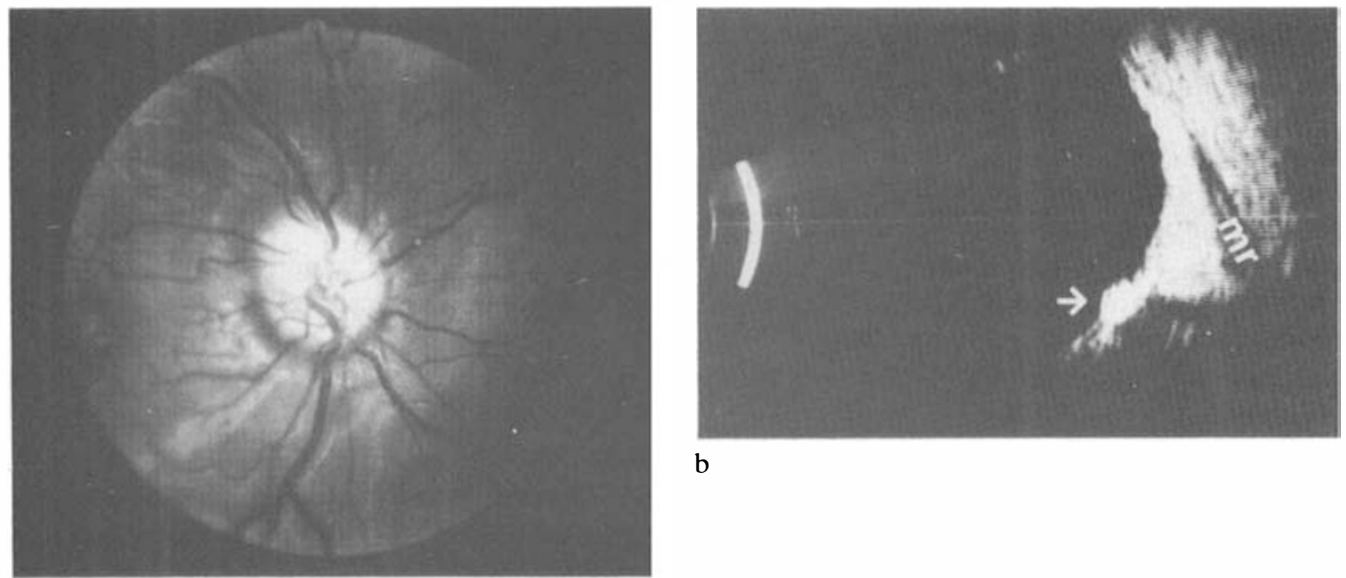

b

a
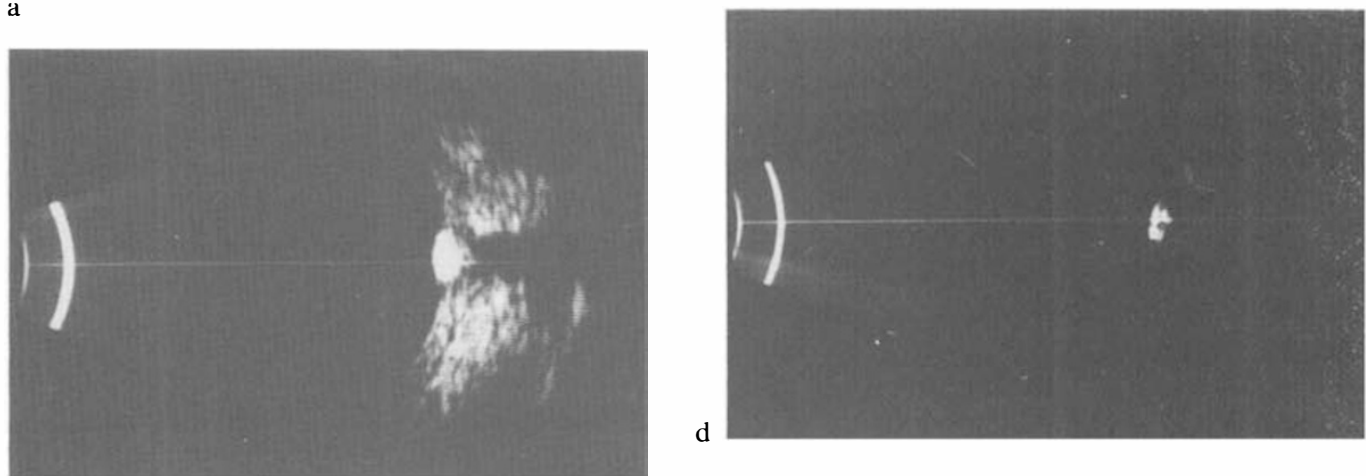

c
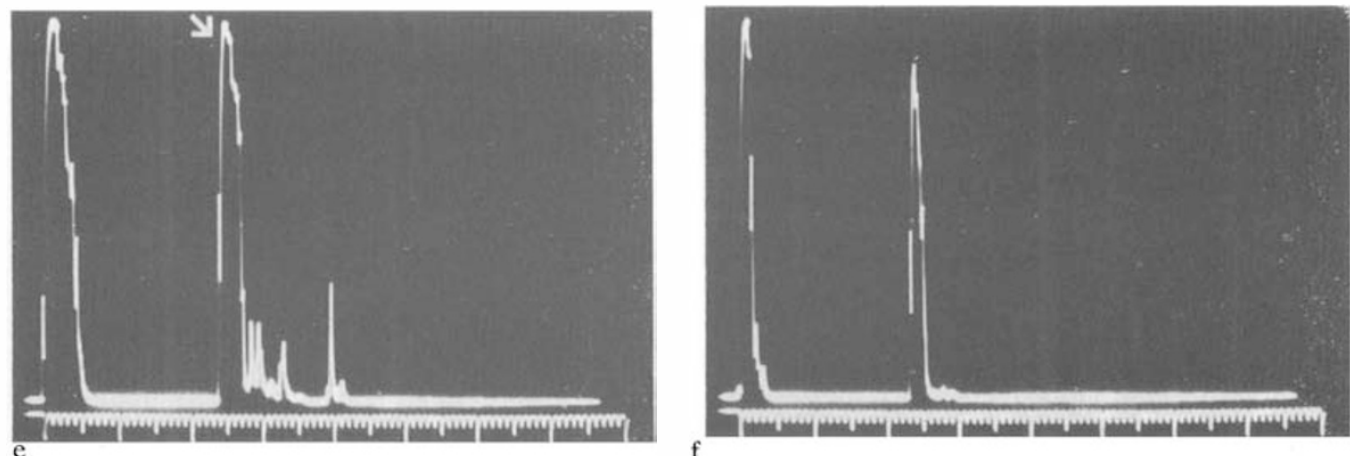

Fig. 7. Optic Disc Drüsen. (a) deep-seated drüsen produce smooth disc elevation. (b) longitudinal section, high sensitivity, B-scan display showing a high reflective round drüsen plaque on the optic disc (arrow). Note the dark area behind the drüsen indicating shadowing. MR=medial rectus muscle. (c) transverse section, medium sensitivity, B-scan showing the drüsen in the centre of the echograph. Reducing the sensitivity has enhanced the shadowing effect. (d) the sensitivity setting is greatly reduced. Echoes from normal orbital structures have disappeared except that from the drüsen. (e) standardised A-scan picture at "tissue sensitivity" showing an extremely high spike from the drüsen (arrow). The orbital signals behind the drüsen are reduced because of shadowing. (f) low sensitivity A-scan display showing persistence of the drüsen spike (corresponding to the B-scan display in (d). 


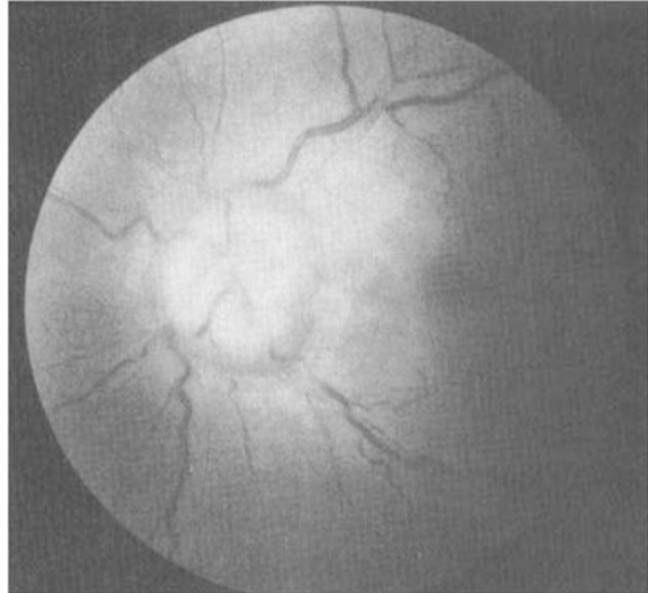

a

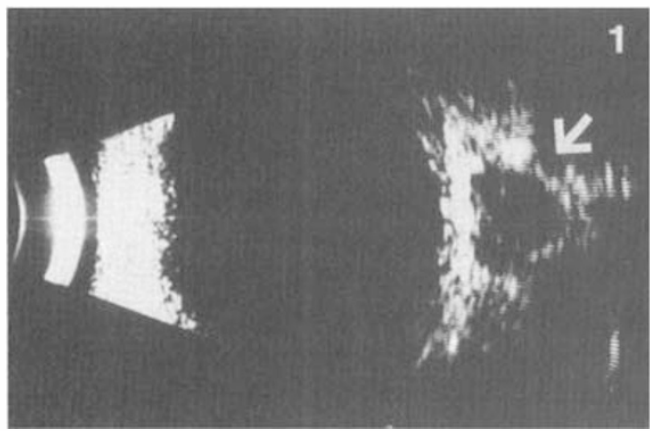

c

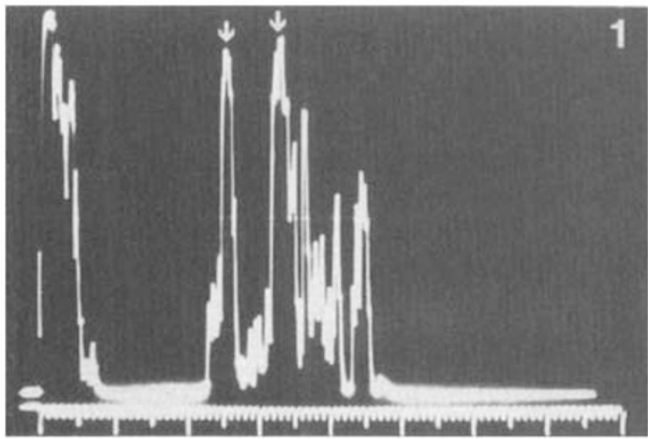

e

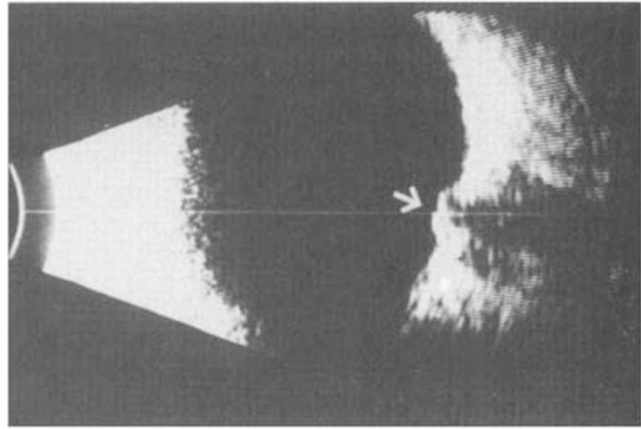

b

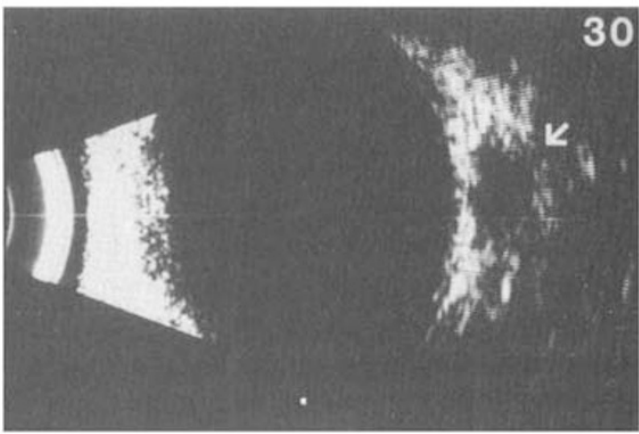

d

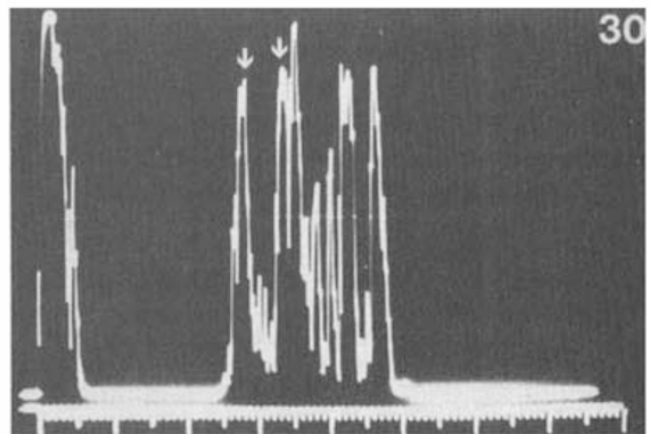

f

Fig. 8. Increased Subarachnoid Fluid (Benign Intracranial Hypertension). (a) fundus photograph demonstrating disc oedema. (b) B-scan echograph showing elevation of the optic disc (arrow). No accurate assessment of the width of the retrobulbar nerve can be made on this display. (c) transverse B-scan of the optic nerve and standardised A-scan (d) at the primary gaze. The void of the optic nerve on B-scan appears abnormally large (arrow) and precise measurement of the nerve width on the A-scan (between arrows) is obtained $=4.2 \mathrm{~mm}$. (e) B-scan and standardised $A$-scan $(f)$ were repeated at $30^{\circ}$ lateral gaze. Although the size of the nerve void seems to be reduced on $B$-scan (arrow), the reduction in width is accurately recorded only by the A-scan (from $4.2 \mathrm{~mm}$ to $3.00 \mathrm{~mm}$ ), a $24 \%$ reduction in size, indicating positive $30^{\circ}$ test. 
(Fig 8a) which also demonstrated on B-scan (Fig $8 b)$. Standardised A-scan examination using the $30^{\circ}$ test (Fig 8c, d, e, f) detected increased subarachnoid fluid as evidenced by decrease of nerve width of $24 \%$ on $30^{\circ}$ lateral gaze. Subsequent CT-scan and CSF pressure measurements established the diagnosis of benign intracranial hypertension.

\section{Discussion}

In recent years, CT-scanning has largely superseded other imaging techniques, including echography, as the method of choice in investigating orbital diseases. ${ }^{11}$ Its advantages over echography, particularly Bscan, include its ability to demonstrate lesions in the posterior and apical portion of the orbit and present, easy-to-read, topographic display of both orbits, bony walls, air sinuses and adjacent intracranial structures. The diagnosis of optic nerve diseases by CT-scan relies mainly on the gross anatomical features of nerve lesions. Only little information, however, is obtained on the tissue characteristics of lesions, eg with the use of contrast. Additionally, subtle abnormalities in the nerve, its sheaths, nerve head and the surrounding intraocular tissues may be missed by this technique. Some of its limitations have been described by Jakobiec et al. ${ }^{12}$ Standarised A-scan is an accurate method of measuring the width of the optic nerve in vivo, an accuracy of between 0.3 to $0.5 \mathrm{~mm}$ has been reported by Ossoinig, Cennamo and Byrne..$^{(9)}$ Using the $30^{\circ}$ test it is also sensitive in differentiating increased subarachnoid fluid from solid nerve or sheath lesions (Table II). The validity of the $30^{\circ}$ test in detecting increased subarachnoid fluid has been confirmed by surgical exploration of the nerve. ${ }^{13,14,15}$

When the special examination techniques are employed (Table I), tissue differentiation of nerve lesions can be made by examining the available acoustic criteria, particularly those obtained with quantitative echography. Standardised A-scan is therefore essential in the echographic examination of the optic nerve and the orbit. Contact B-scan is useful in demonstrating abnormalities in the nerve head and detecting small calcium foci, eg in drüsen and meiningioma. It is inferior to standardised A-scan in measuring the nerve width and differentiating between fluid and solid nerve swelling.

In summary, standardised echography is a useful method, independent and complimentary to CT-scanning, in the investigation of optic nerve diseases. Its safety, low cost and acceptability by patients makes it an ideal method of initial screening and serial examinations of the orbit. As with other diagnostic modalities, the expert use of the appropriate instruments is important to achieve the full potential of this technique.

I wish to thank Mr. M. R. Paul, FRCS, and Mr A W Sollom, FRCS, for their permission to report on their patients.

\section{References}

${ }^{1}$ Ossoinig KC: Standardized echography: basic principles, clinical applications, and results. Int. Ophthalmol. Clin. 1979, 19: 127-210.

${ }^{2}$ Ossoinig KC: Echography of the eye orbit and periorbital region. In Orbital Roentgenology, PH Arger, Ed. Wiley, New York, 1977: 224-269.

${ }^{3}$ Byrne SF and Saclarides EE: Standardized ophthalmic echography and the health care professional. J Opthalmic Nurs. Technol. 1982, 1: 19-27.

${ }^{4}$ Byrne SF and Glaser JS: Orbital tissue differentiation with standardized echography. Ophthalmology 1983, 90: 1071-90.

${ }^{5}$ Byrne SF: Standardized echography of the eye and orbit. Neuroradiology 1986, 28: 618-40.

${ }^{6}$ Till P: Solid tissue model for the standardization of the echo-ophthalmograph $7200 \quad$ MA (Kretztechnik). Doc. Ophthalmol. 1976, 41: 205.

${ }^{7}$ Till $\mathrm{P}$ and Ossoinig KC: First experiences with a new solid tissue model for the standardization of A-scan and B-scan instruments used in tissue diagnosis. In D White, R E Brown, Eds., New York. Ultrasound in Medicine 1977: 2167-2174.

${ }^{8}$ Coleman DJ, Lizzi FL, Jack RL: Ultrasonography of the eye and orbit. Lea and Febiger, Philadelphia, 1977: 331 .

${ }^{9}$ Ossoinig KC, Cennamo G, Byrne SF: Echographic differential diagnosis of optic nerve lesions. Doc. Ophthalmol. Proc. Ser. 1981, 29: 327-31.

${ }^{10}$ Byrne SF: Evaluation of the optic nerve with standardised echography. In Smith JL, Ed., Neuro Ophthalmology Now 1986: 45-66.

11 Wright JE: Current Concepts in Orbital diseases (Doyne lecture). Eye 1988, 2: 1-11. 
12 Jakobiec FA: et al., Combined clinical and computed tomographic diagnosis of orbital glioma and meningioma. Ophthalmology 1984, 91: $137-55$.

${ }^{13}$ Lawton Smith J, Hoyt WF, Newton TH: Optic nerve sheath decompression for relief of chronic monocular. choked disc. Am. J. Ophthalmol. 1969, 68: 633-4.
${ }^{14}$ Conn H, Tenzel RR, Lawton Smith J: Optic disc changes with intracranial subarachnoid cysts. $J$. Clin. Neuro-ophthalmol. 1982, 2: 183-92.

${ }^{15}$ Hupp SL, Glaser JS, Byrne SF: Optic nerve sheath decompression. Arch Ophthalmol. 1987, 105: 386-9. 